\title{
Goethals' Infrastructure Challenge Part 2: The Challenge Begins
}

\author{
Major Berndt Spittka P.E., U.S. Military Academy \\ Major Erik R. Wright PE, U.S. Military Academy
}

Major Erik Wright is an Instructor in the Department of Civil and Mechanical Engineering at the United States Military Academy. Erik's civilian education includes a BS in Civil Engineering from Rose-Hulman Institute of Technology, a Master's of Civil Engineering from Norwich University and a MS in Civil Engineering from Purdue University. MAJ Wright is a Registered Professional Engineer in Indiana. MAJ Wright's military education includes the Engineer Officer Basic Course, Maneuver Captain's Career Course and the Joint Engineer Operations Course. Erik has served three one-year tours in Baghdad, Iraq with the most recent tour ending in June 2010. During that tour, Erik was an Infrastructure Analyst with various infrastructure related duties such as data collection and management, condition analyses of infrastructure systems, and functional subject matter expert for validating national critical infrastructure assets. Past assignments include: Forward Engineer Support Team - Main Detachment Commander; Platoon Leader; Infrastructure Analyst at Corps Level; Civil Engineer, Plans Officer and Logistics Officer at Battalion Level. Erik's Current research focuses on the construction of nuclear facilities and the criticality of infrastructure systems. He is an active member of the American Society for Engineering Education, the American Society of Civil Engineers and a life member of the Society of America Military Engineers. He has been married to his wife Melissa for 10 years and has two children, Alexander (9) and Merideth (6).

\section{Dr. Steven D Hart, U.S. Military Academy \\ Evan Hansen}




\section{Goethals' Infrastructure Challenge Part 2: The Challenge Begins}

Students will do just about anything asked of them, if their professors are willing to ask. The Goethals' Infrastructure Challenge (GIC) by design inspires students to envision a better future, unleash their creativity, and apply their social, technical, political, and economic skills to address a "wicked problem." Building on work from last year, West Point in conjunction with the US Army Engineer Research and Development Center (ERDC), completed the small-scale pilot test for the GIC with stellar results. The focus of this pilot was to prove the concept that an openended question and online-based competition can inspire students to achieve unique and applicable solutions to some of our most complex infrastructure problems, while meeting some of the most challenging ABET student outcomes required of civil engineering programs. Using proven metrics for evaluating student performance, the GIC pilot has shown that those who are asking students the questions in civil engineering student competitions have been the limiting factor for creativity. During this pilot, a four-day competition, the students were able to create a solution to a wicked problem that encompassed not only a technical solution, but also addressed the problem's political, social, and economic aspects. The results show that once students receive the right questions they will try to (and do) rise to whatever challenge is presented to them. With a successful small-scale pilot completed and upon the success of the large-scale pilot, the GIC will be offered nationwide starting in the spring of 2015.

\section{Introduction}

The developers of the Goethals’ Infrastructure Challenge wanted students to solve wicked problems and wanted to fill an identified gap in competition-based learning. The BOK2 assessment tool measures this gap utilizing 24 metrics that are expected skills in professional practice. Before the competition is implemented nationally, a small-scale and a large-scale test run will be conducted. For the small-scale test run, the GIC was run on 6-8 December 2013 at West Point with three teams made up of five Cadets.

The GIC will run a large-scale test on 3-6 April 2014. The large-scale test will run at several universities, and the results from the large-scale test run will be presented as they become available.

The GIC pilot program incorporates Likert and free-response surveys to gauge whether the GIC met the perceived student learning outcomes. The results of those surveys helped to address the proposed research questions. The proposed research questions are: Does the GIC meet its proposed educational objectives? And, does the GIC meet the previously identified gap in competition based learning activities for civil engineers?

\section{Literature review}

The problems faced by engineers are no longer purely technical. The problems faced now fall into several categories. As Hart and Spittka ${ }^{1}$ discussed in 2013, purely technical problems, where a solution can be optimized, are being joined by wicked, social-technical, and complexadaptive problems. 
Infrastructure problems are also characterized as wicked after the concept of Rittel and Webber. ${ }^{2}$ Rittel and Webber listed ten characteristics of wicked problems yet offered no formal definition of the term. Wicked problems can generally be characterized by a lack of agreement on what the problem is, a lack of agreement on the evaluation metrics, a lack of agreement on potential acceptable solutions, and the inability to optimize to achieve the best solution. These externalities to the problem compound with the fact that every attempt to solve the wicked problem irreversibly changes the system in question and the problem itself-there are no Mulligans, or second shots, when it comes to wicked problems. Unlike technical problems, wicked problems are never solved; they are merely temporarily resolved and transformed. As we look into the future, technical problems have not gone away, but they have been joined by socialtechnical, wicked, complex-adaptive, complex-evolving, and other yet-to-be determined problem characterizations. It is this recognition that has led the NAE and ASCE to challenge the engineering profession to take a leadership position in these problem spaces.

When one also considers that the solution to many technical problems can be commoditized and outsourced $^{3}$, it is imperative that our students are able to solve not only technical problems but also ones of the social-technical, complex adaptive, and wicked varieties.

In order for our students to be able to solve these diverse problem sets, they must be challenged in these types of problems during their educational experiences. One means of challenging students is to use competition-based learning. As Barry, Meyer, Arnett and Spittka ${ }^{4}$ discussed in 2013, the current offers of civil engineering student competitions meet only some of the BOK2 objectives. The research conducted addressed a Likert-scale survey to Civil Engineering programs that asked them to rate the perceived educational impact of competition based learning events on the students' fulfillment of the BOK2 student educational objectives.

Looking across the full data set that Barry, et. al., analyzed, it can be observed that none of the eleven evaluated competitions earned a perceived educational value score higher than or equal to 4.00 in Natural Sciences, Humanities, Social Sciences, Sustainability, Breadth, Public Policy, Business \& Public Administration, Globalization, and Lifelong Learning. Yet, the importance of each of these Outcomes in the process of developing well-prepared civil engineers is evidenced by their inclusion in the BOK2.

Even more critically, none of the following categories scored over a 3.5, Humanities, Social Sciences, Sustainability, Breadth, Business and Public Administration, Globalization.

In order to fill the gap of these unmet educational objectives, Hart and Spittka ${ }^{5}$ proposed the following educational objectives and participant outcomes for the Goethals’ Infrastructure Challenge:

Challenge Educational Objectives:

1. Lead in the discussion, understanding, and making of public infrastructure policy.

2. Employ creative and critical thinking in the resolution of "wicked" problems. 


\section{Participant Outcomes:}

1. Solve interdisciplinary problems as a member of a team.

2. Formulate problem and solutions sets to 'wicked' problems.

3. Present and defend a proposed infrastructure solution in a public forum.

4. Integrate social, political, economic, sustainability, resilience, and technical factors in solving infrastructure problems.

These objectives are focused on the participants of the competitions. The products that the participants create are expected to be very good, but the real goal of the competition is to educate future generations of professionals on how to approach and solve problems of the wicked variety.

In order for students to embrace solving wicked and other complex problems, they must be motivated to do so. What is viewed as traditional motivation, or in Daniel Pink's vernacular Motivation 2.0, involves carrots and sticks. The rewards and punishments for doing well or not are imposed extrinsically on the students. Pink argues that the external based system of Motivation 2.0 is no longer (or possibly never was) as effective as the internal based motivation of an individual. ${ }^{6}$ In order to inspire students to internal motivation, the manner in which tasks and rewards are structured must be adjusted. The students must feel they have three elements in the work they are accomplishing: autonomy, mastery (or the ability to strive toward mastery), and purpose. ${ }^{7}$ In order for students to be motivated to discover how to solve the complex problems facing today's professionals, they must be given the latitude to develop their own internal motivation.

Autonomy speaks to the desire of humans to be their own masters. People want to feel like they have the ability to control their own destiny by picking and choosing where they place their efforts. Pink argues that we move beyond Motivation 2.0 and closer to internal motivation when we have the ability to work autonomously. ${ }^{8}$ Mastery is becoming proficient at ones' chosen craft. In the same way that a basketball player shoots the same shot hundreds of thousands of times in practice for the opportunity to shoot one time at the end of a game, so too do all professionals seek to become masters within their domain. Allowing professionals and students the opportunity to work towards mastery helps move us beyond Motivation 2.0. ${ }^{9}$ Finally, Purpose allows a person to see the reason why their efforts are important. Most people want to be functional members of a team and have their efforts used as part of a larger project, or the entire project. This purpose means something more than just their current paycheck or grade. ${ }^{10}$

\section{Methods}

The GIC competition structure gives teams a small focused amount of time that allows them to be brilliant and come up with a unique solution to a wicked problem. ${ }^{11}$ Hart and Spittka looked at doing a yearlong or a 96-hour competition. ${ }^{12}$ They chose the 96-hour version of the competition, with future parts of the Goethals' family of competitions looking to incorporate the yearlong competition option. The relatively short duration of the competition was chosen so the GIC had minimal long-term impact on the already encumbered ABET accredited civil engineering curriculum. The effectiveness of professionals being able to enhance their overall performance and creativity by working for a focused amount of time is being extended to the 
undergraduate level as well. The intent was not to replace, but to augment, the activities already in a civil engineering curriculum.

All of the materials and direction for the competition are given to the participants through the competition's website, http://infrastructurechallenge.org. The GIC teams are limited only by size; there are no more than five people allowed on each team. The teams are given the generic challenge topic areas before the competition window. At the start of the 96-hour timeframe, the exact challenge in each of the topic areas is posted to the website. The teams submit all of their challenge solutions on the website as well. Participants of the competition retain all intellectual property. Beyond these constraints, there were no other rules imposed on the competitors for the completed small-scale test.

Hart and Spittka looked at having three submission requirements: 1. A 7,500 word position paper 2. A 500 word OP-ED style piece and 3. A video presentation to the judges. ${ }^{13}$ The final GIC submission required four total submission: 1. A 7,500 word position paper 2. A 500 word OP-ED style piece 3 . A one-power point slide that acts as the sales brochure to the general public and 4. A video of the 60-second elevator pitch of the proposed solution.

\section{Small Scale Test}

On 6-8 December 2013, three teams of five cadets were given 72-hours to complete only the position paper submission requirement for a solution to one of three provided prompts. The three prompts were in the topic areas of transportation, water, and energy. The prompts are provided in Appendix A. Cadets from CE350: Infrastructure Engineering were chosen to participate in the competition. One participant came from the USMA Geography and Environmental Engineering Department as well. The authors offered the GIC to a select number of students who had performed well on examinations and assignments in the current semester of CE350. Then, importantly, the students were allowed to structure their own groups. Two groups addressed the regional transportation prompt, while one group addressed the wastewater prompt. The groups were allocated space in the USMA engineering building, but were in no ways constrained on their use of the time. One group had a member that became ill over the weekend, so the ill cadet worked from his room while still contributing, even utilizing video teleconferencing (VTC) to help with his team's submission requirements.

Five judges reviewed the submissions and scored the position papers based upon the rubric that is in Appendix B. The judges came from the Civil Engineering Division and the Environmental Engineering Division of West Point, as well as the Department of Homeland Security.

At the completion of the competition, the participants were given an individual survey using SurveyMonkey ${ }^{\circledR}$. The survey addressed their experiences with the competition, the website, and their perceived educational benefit. The survey included Likert scale responses as well as free response questions. The complete survey is found in Appendix C.

The survey required respondents to evaluate the perceived educational value of individual competition-based learning activities relative to the 24 outcomes identified in the BOK2. ${ }^{14}$ Each outcome was evaluated as being "Not Applicable" (Outcome is not satisfied by this competition), "Very Limited" (Outcome is satisfied to a very limited extent by this competition), "Somewhat" 
(Outcome is somewhat satisfied by this competition), "Significantly" (Outcome is significantly satisfied by this competition), or "Completely" (Outcome is completely satisfied by this competition). A definition of each outcome was provided within the survey using the precise language that ASCE uses in the BOK2 document. Refer to Appendix C to read the list of Outcomes and associated definitions.

The survey required respondents to evaluate whether the competition met the proposed student educational outcomes of the Goethals' Infrastructure Challenge. Each outcome was evaluated as being "Not Applicable" (Outcome is not satisfied by this competition), "Very Limited" (Outcome is satisfied to a very limited extent by this competition), "Somewhat" (Outcome is somewhat satisfied by this competition), "Significantly" (Outcome is significantly satisfied by this competition), or "Completely" (Outcome is completely satisfied by this competition). A definition of each outcome was provided within the survey using the same language as the proposed Goethals' Infrastructure Challenge student outcomes. Refer to Appendix C to read the list of outcomes.

The evaluator survey was used to gauge how well the students performed on the GIC, the perceived educational benefit to the students and to help develop the evaluation metrics of the challenge going forward. The survey included Likert scale responses as well as free response questions. The complete survey given to the evaluators can be seen in Appendix D. The survey used the same BOK2 criteria and proposed Goethals' Infrastructure Challenge Student Outcomes as the participant survey.

Limited manipulation of the collected survey data was required.

\section{Large Scale Test}

The large-scale test will be run from 3-6 April 2014. Student teams from 7 universities will be given 96-hours to complete a position paper, Op-Ed newspaper article, elevator speech, and concept poster. All materials will be available to the participants via the Goethals' Infrastructure Challenge website, http://infrastructurechallenge.org. The submissions will be submitted through the website as well.

The participants of the large-scale test will be given a SurveyMonkey ${ }^{\circledR}$ survey that is similar to the small-scale test survey. However, the large-scale test survey will incorporate lessons learned from the small scale test.

The evaluators of the large-scale test will be given a SurveyMonkey survey that is similar to the small-scale test survey but incorporated lessons learned from the small scale test into the new survey.

Since multiple universities will be involved in the large-scale test, the faculty advisors for the large-scale test will be given a SurveyMonkey ${ }^{\circledR}$ survey that is similar to the evaluators' survey. 


\section{Results}

The survey given to the participants of the small-scale test resulted in 14 responses. This was a 93\% response rate. Three evaluators of the small-scale test completed the survey for a 50\% response rate. All responses were included in the results, since no incomplete or bad data was received.

Table 1 is a summary of the perceived education benefit of the Goethals' Infrastructure Challenge based on the BOK2 student educational outcomes. The average of the participants' and the evaluators' responses to the Likert-scale survey are listed below. The scores for objectives that participants rated lower than evaluators are underlined in the Table 1.

Table 1: Average Reported Percieved Student Educational Value of GIC

\begin{tabular}{|ccc}
\hline BOK2 Objective & $\begin{array}{c}\text { Participant } \\
\text { Responses }\end{array}$ & $\begin{array}{c}\text { Evaluator } \\
\text { Responses }\end{array}$ \\
\hline Math & 2.92 & 2.33 \\
\hline Natural Sciences & 3.15 & 2.00 \\
\hline Humanities & 4.31 & 4.00 \\
\hline Social Sciences & 4.15 & 4.00 \\
\hline Material Science & 3.08 & 2.33 \\
\hline Mechanics & 3.08 & 2.33 \\
\hline Experiments & 2.17 & 2.33 \\
\hline Problem Recognition & 4.77 & 3.00 \\
\& Solving & & \\
\hline Design & 4.69 & 3.33 \\
\hline Sustainability & 4.62 & 3.33 \\
\hline Contemporary Issues & 4.54 & 3.67 \\
Risk \& Uncertainty & 3.77 & 3.00 \\
\hline Project Management & 4.08 & 2.67 \\
\hline Breadth & 4.23 & 2.67 \\
\hline Technical & 4.08 & 2.00 \\
\hline Specialization & & \\
Communication & 4.54 & 4.33 \\
\hline Public Policy & 4.54 & 4.00 \\
\hline Business and Public & 4.38 & 3.33 \\
Administration & & \\
\hline Globalization & 3.85 & 3.33 \\
\hline Leadership & 4.46 & 3.00 \\
Teamwork & 4.85 & 4.67 \\
Attitudes & 4.15 & 3.00 \\
\hline Lifelong Learning & 4.31 & 3.67 \\
Professional \& & 4.08 & 4.33 \\
\hline Ethical Responsibility & & \\
\hline Average & 4.03 & 3.19 \\
\hline
\end{tabular}


Figures 1 and 2 are summaries of the proposed Goethals' Infrastructure Challenge Participant Educational Outcomes. The average of the participants' (Figure 1) and the evaluators' (Figure 2) responses to the Likert-scale survey are listed below. The spectrum of scores range from a minimum of 1.0 to a maximum of 5.0 .

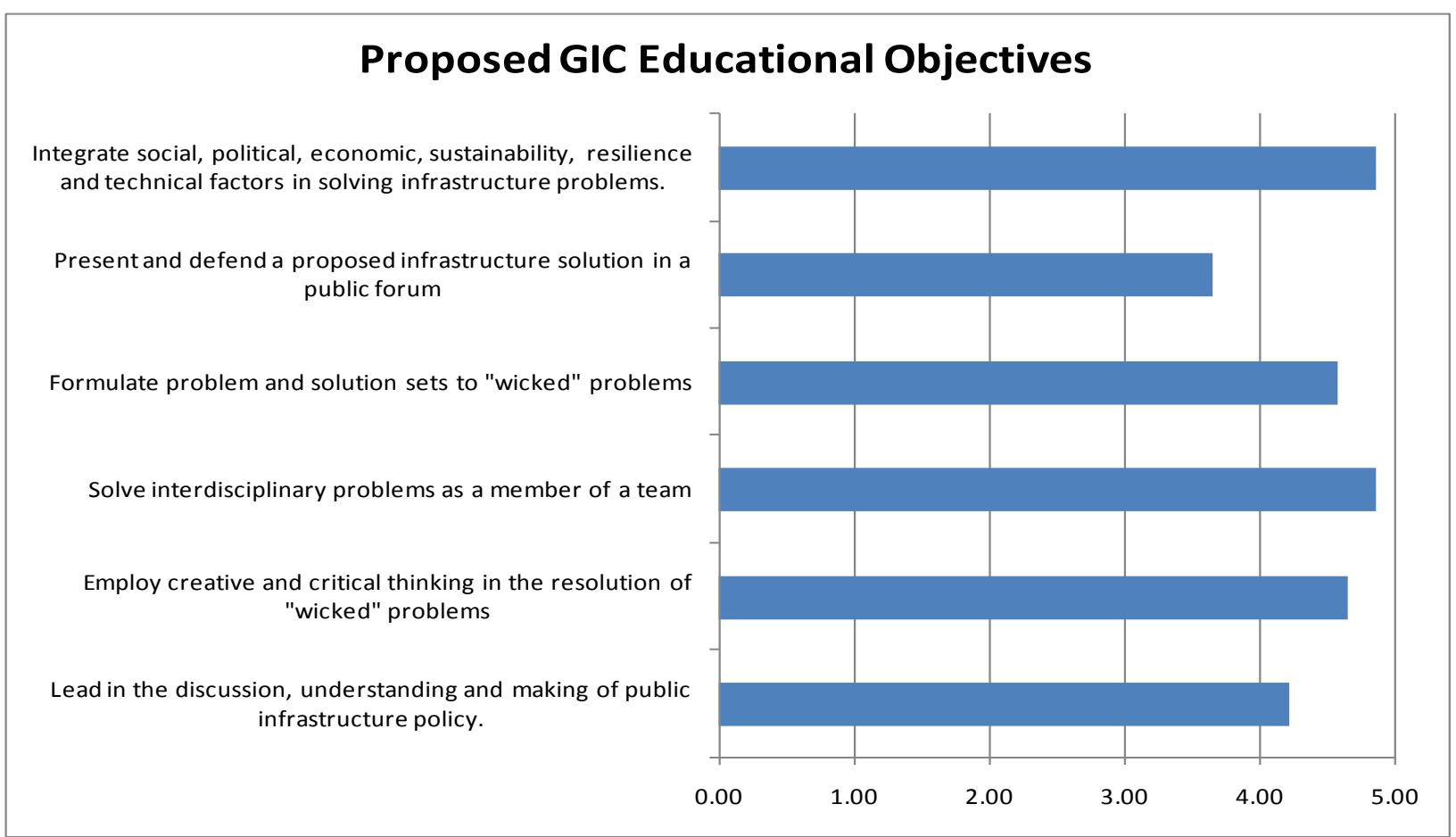

Figure 1: Goethals’ Infrastructure Challenge Participant Education Outcomes- Participant

\section{Proposed GIC Educational Objectives}

Integrate social, political, economic, sustainability, resilience and technical factors in solving infrastructure problems.

Present and defend a proposed infrastructure solution in a public forum

Formulate problem and solution sets to "wicked" problems

Solve interdisciplinary problems as a member of a team

Employ creative and critical thinking in the resolution of "wicked" problems

Lead in the discussion, understanding and making of public infrastructure policy.

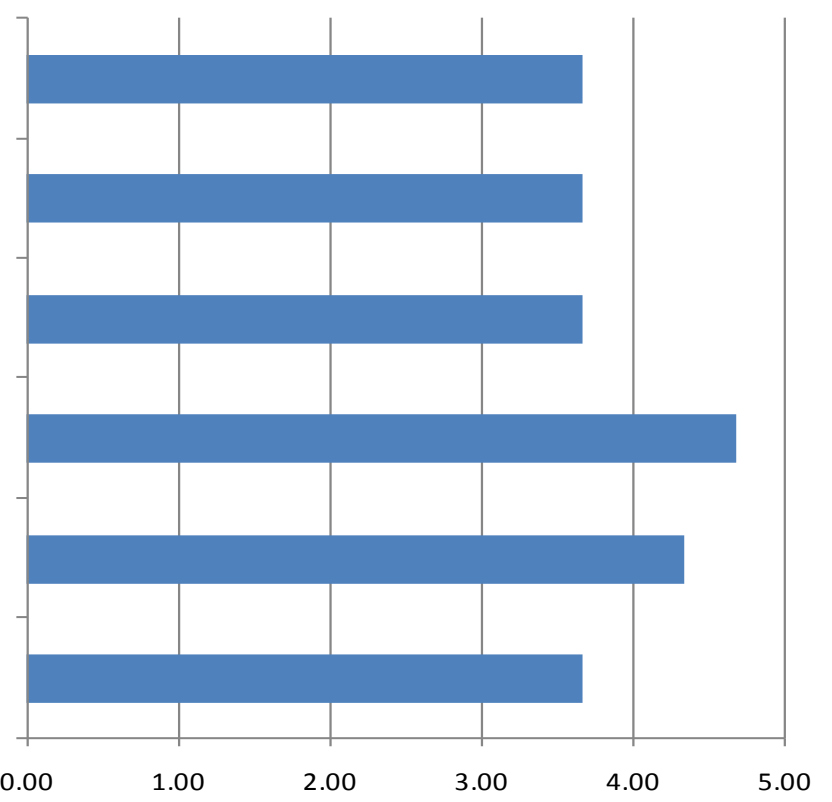

Figure 2: Goethals’ Infrastructure Challenge Participant Education Outcomes- Evaluator 
Table 2 and 3 show the time spent by participants (Table 2) and evaluators (Table 3) on their respective tasks associated with the Goethals' Infrastructure Challenge. The time spent is reported in Hours.

Table 2: Time Spent on Goethals’ Infrastructure Challenge- Participant Input

\begin{tabular}{|l|r|r|r|}
\hline $\begin{array}{l}\text { Average } \\
\text { (hours) }\end{array}$ & Research & Problem Formulation & Writing Position Paper \\
\hline
\end{tabular}

Table 3: Time Spent on Goethals’ Infrastructure Challenge- Evaluator Input

\begin{tabular}{|c|c|}
\hline & Evaluating each Position Paper \\
\hline Average (hours) & 1.1 \\
\hline
\end{tabular}

Table 4 shows the participants response to what other courses helped them in completing the GIC Challenge. The number of times, each course was mentioned is shown in the right hand column.

Table 4: Courses that helped participants in the Goethals’ Infrastructure Challenge.

\begin{tabular}{|ccc}
\hline Course Name & $\begin{array}{c}\text { Course } \\
\text { Number }\end{array}$ & Mentioned \\
\hline Civil Engineering Site Design & CE390 & 7 \\
Economics & SS201/SS251 & 4 \\
American Politics & SS202/SS252 & 3 \\
\hline $\begin{array}{c}\text { Analytical Method for Engineering } \\
\text { Management }\end{array}$ & EM384 & 1 \\
Engineering Economy & EM381 & 1 \\
\hline $\begin{array}{c}\text { Environmental Systems Analysis } \\
\text { Environmental Systems Design }\end{array}$ & EV401 & 1 \\
$\begin{array}{c}\text { Fundamentals of Engineering Mechanics and } \\
\text { Design }\end{array}$ & EV402 & 1 \\
\hline $\begin{array}{c}\text { Mass Media and American Politics } \\
\text { Mechanics of Materials }\end{array}$ & SS370 & 1 \\
Physical Geography & MC364 & 1 \\
$\quad$ Physics & EV203 & 1 \\
\hline Probability \& Statistics & PH201/PH202 & 1 \\
Statistics for Engineers & MA206 & 1 \\
\hline
\end{tabular}

The GIC aims at developing the next generation of critical thinkers, thus the competition must appeal to engineers and future engineers. The participants responded to a free response question that asked them what they liked about the competition and if they would do it again. Twelve out of 14 participant responses said they would participate again. The other two responses said they would participate again given the right set of circumstances. 
Table 5 shows the participants responses to what they liked about the competition.

Table 5: What Participants Liked about the GIC

The opportunity to solve a real world problem with not just engineers, but people from other majors. Just like it will be outside of West Point.

I liked the openness of the prompts.

The fun times and cool problems

Working with my team on a project that had no clear answer. It was a great deal of work but it felt like we were really accomplishing. This was only magnified by the excitement of all of the random professors who came to see us.

Solving a complex problem with little or no guidance. Being able to plan a project with $100 \%$ autonomy from start to finish. Working with cadets from other majors.

Working with a team to solve a complex problem.

It really required teamwork and cooperation.

Group interaction and teamwork across multiple disciplines

I felt like a real engineer. Also, I felt like the things we learned about in class were actually applicable

I enjoyed tackling a real world application

I learned a lot about High Speed Rails. I feel it increased my ability to think critically and be creative and look for solutions and research

I appreciated how open ended the challenge was due to there not being many questions like that given at West Point. I also like having a choice of three topics.

Group Project. Time length

It allowed me to integrate cross disciplinary knowledge.

\section{Discussion}

The results from the small-scale test showed that the GIC has formulated applicable academic participant outcomes. The participants felt that they met all of the academic outcomes between 4.0 (Significantly) and 5.0 (Completely). The only outcome that was not above 4.0 was "Present and defend a proposed infrastructure solution in a public forum." Since the participants did not have to complete all the submission requirements that required them to publically defend their proposal, it was expected that this outcome would be reported lower that the others.

The evaluators did not perceive that the participants satisfied the educational outcomes to the same extent that the participants did. This discrepancy can be attributed to the relative experience the evaluators have when compared to the participants. The evaluators still felt that two of the outcomes were between 4.0 (Significantly) and 5.0 (Completely) met. Those outcomes were "Employ creative and critical thinking in the resolution of 'wicked' problems" and "Solve interdisciplinary problems as a member of a team." The fact that the Goethals' Infrastructure Challenge wants to develop the participants to think about difficult problems more deeply and is looking for an interdisciplinary approach to those problems means that the primary educational outcomes for the GIC have been met at a high level by the small-scale test.

Two other objectives that are rated between 3.0 (Somewhat) and 4.0 (Significantly) by the evaluators speak directly to the quality of the submissions that the participants generated. Those 
objectives are "Formulate problem and solution sets to 'wicked' problems" and "Integrate social, political, economic, sustainability, resilience and technical factors in solving infrastructure problems." Since the survey asked the evaluators to rank the submissions as a whole (not individually) the overall average of the submissions were below the "significantly level", while some of the submissions were over the "significantly" level for those two outcomes.

The GIC has also shown through a survey that the gap identified in BOK2 objectives by Barry, Meyer, Arnett, and Spittka is lessened by this new student competition. The BOK2 objectives, as reported by Barry, et. al., that were not over 3.5 for any existing competition were: Humanities, Social Sciences, Sustainability, Breadth, Business and Public Administration, Globalization. Both participants and evaluators felt that the GIC scored at least a 4.0 for the Humanities and Social Sciences outcomes. This is a significant increase over any current student competition, where both of those objectives scored under a 3.5. Sustainability; Breadth; Business and Public Administration all scored over a 4.0 from the participants and under a 3.5 from the evaluators. The students' perception of their educational benefit was higher than the evaluators' perception, which is expected given the complexity of the BOK2 objectives. The discrepancy can also be attributed to the comparative lack of professional experience that the participants have, which is contrasted with the experience the evaluators have.

Of the BOK2 outcomes that Barry, et. al reported, the one outcome that was under 4.0 from both the students and evaluators in the small scale test survey was Globalization. The nature of the questions that were posed in the small-scale test of the GIC makes this response on the survey make sense. All prompts for the small-scale test were focused on the United States.

The GIC developers will continue to look at adjusting the GIC to incorporate the need for a student competition that can further address Sustainability; Breadth; Business and Public Administration; Globalization.

The GIC aims at developing the next generation of critical thinkers, so the competition needs to be something that participants want to be a part of. It is important to note that none of the participants said they would not do the competition again. The range of reasons why the participants liked the competition shows that the competition is developed to appeal to a wide range of participants. Participants were willing to spend large amounts of time in the midst of demanding schedules because they thought the challenge was something worth working on.

\section{Summary Findings}

The first research question posed in this study was whether the GIC met its proposed educational objectives. Based on the findings from the Likert surveys of the participants and evaluators, the small-scale test of the GIC met some, but not all of the proposed educational objectives as was hoped for. Some of the educational objectives were not expected to be met (Present and defend a proposed infrastructure solution in a public forum). Others will vary with each iteration of the GIC since they are based on the quality of the participant's submittals (Formulate problem and solution sets to "wicked" problems; and Integrate social, political, economic, sustainability, resilience and technical factors in solving infrastructure problems). 
The second research question posed in this study was whether the GIC met the previously identified gap in competition based learning activities for civil engineers. Again, the small-scale test of the GIC showed that some, but not the entire gap, was lessened. The BOK2 objectives of Humanities and Social Sciences were both rated at a greater than Significantly level based on the participant and evaluator surveys. There was a discrepancy (Participants perceived greater than Significantly while Evaluators perceived greater than Somewhat level) in whether or not the Sustainability; Breadth; Business and Public Policy were met. Globalization was not met at the greater than Significantly level.

The authors found that the teams in the small-scale test addressed the challenge prompts and focus areas, but the prompts did not give the Cadets enough guidance on the depth of thought needed for the submissions. To ensure that the submissions address the depth of thought required, the large-scale test will include prompts that cause the participants to have to address more issues with their submissions.

The authors do not recommend that the GIC be extended to an entire CE program. The challenge seemed to work well when the participants wanted to be part of the challenge. When they brought some internal motivation to the table, they produced better results. Having a challenge be a mandatory requirement for a full CE program will reduce the inherent internal motivation, which would cause the perceived educational value to decrease. Perhaps this challenge can be utilized and viewed as a reward for high performers who want to be pushed to the next level of critical thinking.

The GIC developers will look to launch a full-scale GIC competition at the national level in the spring of 2015. The developers are currently looking for organizations that are willing to evaluate, provide prize money, and provide challenges they want addressed. 


\section{References}

${ }^{1}$ Hart, S. and B. Spittka. The Goethals Infrastructure Challenge: A Proposal for a New Student Competition. in ASEE Annual Conference and Exposition: Frankly We do Give a D*mn, June 23, 2013 - June 26, 2013. 2013. Atlanta, GA, United States: American Society for Engineering Education.

${ }^{2}$ Dilemmas in a General Theory of Planning. Rittel, Horst W.J. and Webber, Melvin M. 1973, Policy Sciences, pp. 155-169.

${ }^{3}$ Friedman, Thomas L. The World Is Flat: A Brief History of the Twenty-First Century. New York : Farrar, Straus, and Giroux, 2006.

${ }^{4}$ Barry, B., K. Meyer, K. Arnett, and B. Spittka. Competition-Based Learning Activities within Civil Engineering Education: A Critical Review of Current Options. in ASEE Annual Conference and Exposition: Frankly We do Give a $D^{*} m n$, June 23, 2013 - June 26, 2013. 2013. Atlanta, GA, United States: American Society for Engineering Education.

${ }^{5}$ Hart, Goethals: A Proposal.

${ }^{6}$ Pink, Daniel., Drive: The Surprising Truth About What Motivates Us. 2009, New York, NY: Penguin Books, p. 31

${ }^{7}$ Ibid., p. xi.

${ }^{8}$ Ibid., p. 88.

${ }^{9}$ Ibid., p. 113.

${ }^{10}$ Ibid., p. 131.

${ }^{11}$ Hart, LTC Steven. ERDC Engineering Fellow. [interv.] MAJ Berndt F. Spittka. November 11, 2013.

${ }^{12}$ Hart, Goethals: A Proposal.

${ }^{13}$ Ibid.

${ }^{14}$ American Society of Civil Engineers. Body of Knowledge Committee., Civil engineering body of knowledge for the 21st century : preparing the civil engineer for the future. 2nd ed. 2008, Reston, Va.: American Society of Civil Engineers. ix, $181 \mathrm{p}$. 
Appendix A: Fall 2013 Prompts
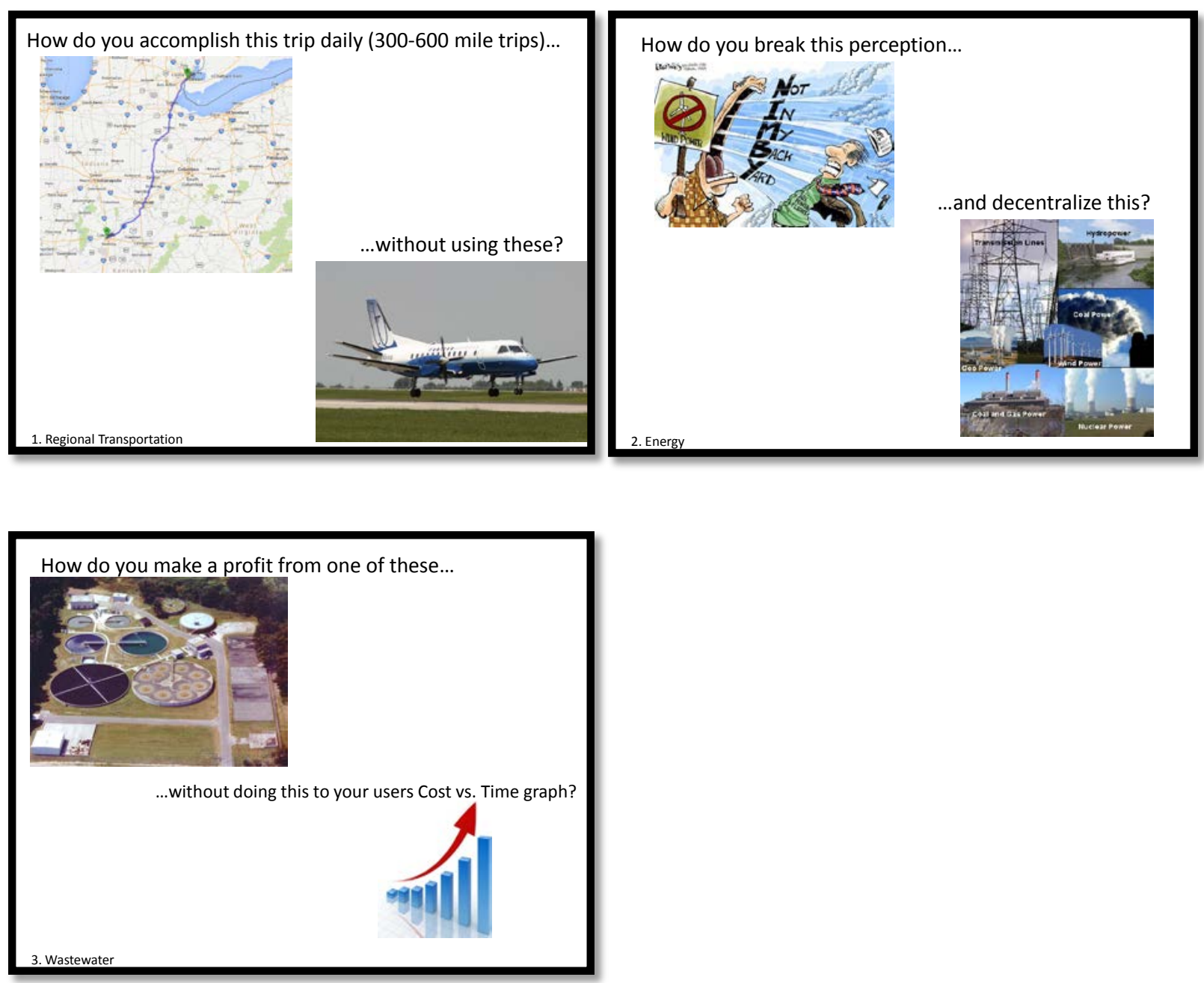

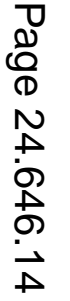




\section{Evaluation Metrics}

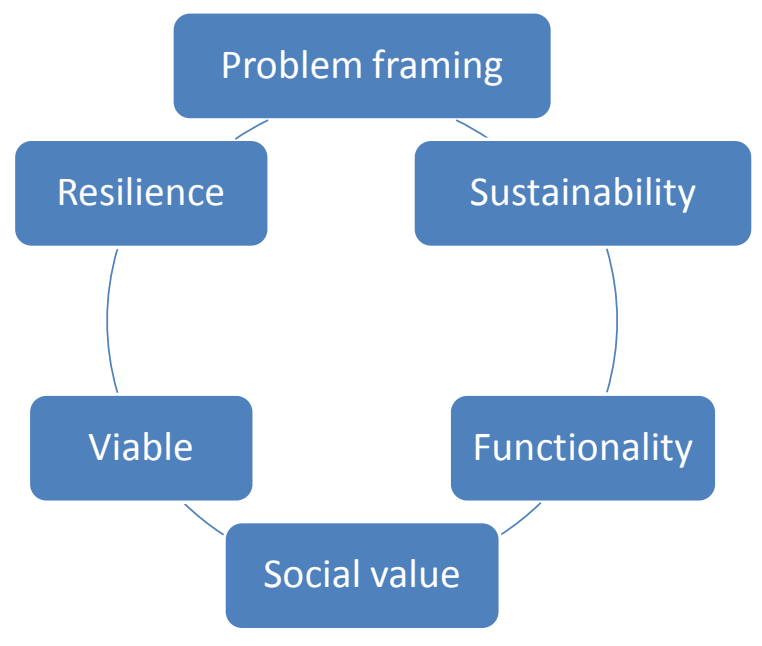

See the future Write the plan Be the answer

\section{Scale of Evaluation Metrics}

\begin{tabular}{|c|c|c|c|c|}
\hline & \multicolumn{4}{|c|}{ Tiers of Quality of Submissions } \\
\hline & 1 & 2 & 3 & 4 \\
\hline Problem Framing & Well Developed & Defined & Loosely Defined & III Defined \\
\hline Resilience & & Considered & & Not addressed \\
\hline Sustainable & & Considered & & Not addressed \\
\hline Viable & Is viable & Might be viable & not currently viable & not able to be viable \\
\hline Functional & highly functional & somewhat functional & may be functional & not functional \\
\hline Social Value & Fully meets the need & Meets the Need & Meets a need & Doesn't meet any need \\
\hline
\end{tabular}

